\title{
Comparative Ultrasonic and Conductometric Studies of Aqueous Sodium Chloride and Potassium Chloride Solutions
}

\author{
VIJAYTA GUPTA, AMIT KUMAR SHARMA and MEENA SHARMA* \\ Department of Chemistry, University of Jammu (J\&K)-180006, India \\ mlakhanpal89@rediffmail.com
}

Received 27 August 2013 / Accepted 6 October 2013

\begin{abstract}
Densities $(\rho)$, viscosities $(\eta)$, ultrasonic velocities $(u)$ and conductivities $(\kappa)$ have been measured by using specific gravity bottle, Ostwald's viscometer, single frequency ultrasonic interferometer (6 MHz frequency) and conductivity meter respectively for aqueous solutions of sodium chloride and potassium chloride at different concentrations $(\mathrm{w} / \mathrm{w})$. Various acoustical parameters viz. adiabatic compressibility $\left(\beta_{\mathrm{ad}}\right)$, intermolecular free length $\left(\mathrm{L}_{\mathrm{f}}\right)$, acoustical impedance $(\mathrm{Z})$, relaxation time $(\tau)$, rao's constant $\left(\mathrm{R}_{\mathrm{M}}\right)$, wada's constant $(\mathrm{W})$, free volume $\left(\mathrm{V}_{\mathrm{f}}\right)$, absorption coefficient $\left(\alpha / \mathrm{f}^{2}\right)$, gibb's free energy $(\Delta \mathrm{G})$, relative association $\left(\mathrm{R}_{\mathrm{A}}\right)$ and available volume $\left(\mathrm{V}_{\mathrm{a}}\right)$ were calculated from these experimental data. The results are interpreted in terms of molecular interactions between components of solutions.
\end{abstract}

Keywords: Viscosities, Ultrasonic velocities, Conductivities, Acoustical parameters, Molecular interactions

\section{Introduction}

Ultrasonic velocity of sound waves in a medium is essentially related to the binding forces between the molecules. Ultrasonic technique has been effectively employed to study the properties of any substance to understand the nature of molecular interactions in pure liquid $^{1}$, liquid mixtures ${ }^{2-5}$ and ionic interactions in electrolytic solutions ${ }^{6-7}$. The physicochemical behaviour and molecular interaction in pure liquid components and their mixtures is studied on the basis of acoustic and thermodynamic properties ${ }^{8}$. Literature survey shows that ultrasonic study of liquid mixture is highly useful in understanding the nature of molecular interaction $^{9-11}$ and physicochemical behaviour of liquid mixture ${ }^{2,12-13}$. Molecular properties in liquid state are very useful in chemical analysis, thermodynamic and physical properties. In the present work, an attempt has been made to investigate the behaviour of binary solutions of water with sodium chloride and potassium chloride with regard to adiabatic compressibility, intermolecular free length, acoustical impedance, relaxation time, rao's constant, wada's constant, free volume, absorption coefficient, Gibb's free energy, relative association and available volume from ultrasonic measurements. The conductivity was also measured at various concentrations. Dissolution of an electrolyte in water is 
accompanied by electrostriction of the solvent beneath the action of electrostatic fields of newly produced ions ${ }^{14}$. Sodium chloride is used as common salt for domestic purpose. It is used to produce sodium carbonate and calcium chloride via the solvay process. Potassium chloride is used in medicine, lethal injections, scientific applications and food processing. It is also used as a fire extinguishing agent. Moreover, it is used for the manufacture of potassium hydroxide and potassium metal.

\section{Experimental}

The chemicals used in the present work were analytical reagent (AR). In all systems, the various concentrations of the binary mixtures were prepared in terms of $\%(\mathrm{w} / \mathrm{w})$. Water used was prepared by distilling ordinary water thrice over alkaline $\mathrm{KMnO}_{4}$ in all glass apparatus. The specific conductance of water so obtained was $1.3 \times 10^{-4} \Omega \mathrm{cm}^{-1}$.

\section{Density measurement}

The density of aqueous solutions is measured using a $10 \mathrm{~mL}$ specific gravity bottle. The temperature is maintained constant by immersing the bottle in Juloba thermostat for $15 \mathrm{~min}$. The density can be calculated using the formula

$$
\rho_{2}=\left(w_{2} / w_{1}\right) \rho_{1} \mathrm{kgm}^{-3}
$$

Where, $w_{1}$, is the weight of the distilled water, $w_{2}$, that of weight of the experimental liquid, $\rho_{1}$, is the density of water, $\rho_{2}$, that of the experimental liquid, Density of water is taken from the literature.

\section{Viscosity measurement}

The viscosity of the aqueous solutions is measured using an Ostwald's viscometer calibrated with doubly distilled water. The Ostwald's Viscometer with the experimental liquid is immersed in a temperature controlled water bath. An electronic stop watch was employed to measure the time of flow. The viscosity can be calculated using the formula,

$$
\eta_{2}=\eta_{1}\left(t_{2} / t_{1}\right)\left(\rho_{2} / \rho_{1}\right) \mathrm{kgm}^{-1} \mathrm{~s}^{-1}
$$

Where, $\eta_{1}$, is the viscosity of water, $t_{1}$, is the time of flow of water, $\rho_{1}$, is the density of water, $\eta_{2}$, is the viscosity of the experimental liquid, $t_{2}$, is the time of flow of the experimental liquid, $\rho_{2}$, is the density of the experimental liquid.

\section{Velocity measurement}

An ultrasonic interferometer is a simple and direct device, Figure 1 to determine the ultrasonic velocity in pure liquids and liquid mixtures with high degree of accuracy. To evaluate ultrasonic velocity, an ultrasonic interferometer provided by mittal enterprises, New Delhi was used as shown in Figure 2. The principle used in the measurement of velocity ' $v$ ' is based on the accurate determination of the wavelength ' $\lambda$ ' in the medium. Ultrasonic waves of known frequency ' $f$ ' are produced by a quartz plate fixed at the bottom of the cell. The waves are reflected by a movable metallic plate kept parallel to quartz plate. Standing waves are formed in the medium if the separation between the plates is exactly a whole multiple of sound wavelength. The acoustic resonance give rise to an electrical reaction on the generator driving the quartz plate and the anode current of the generator become maximum. 


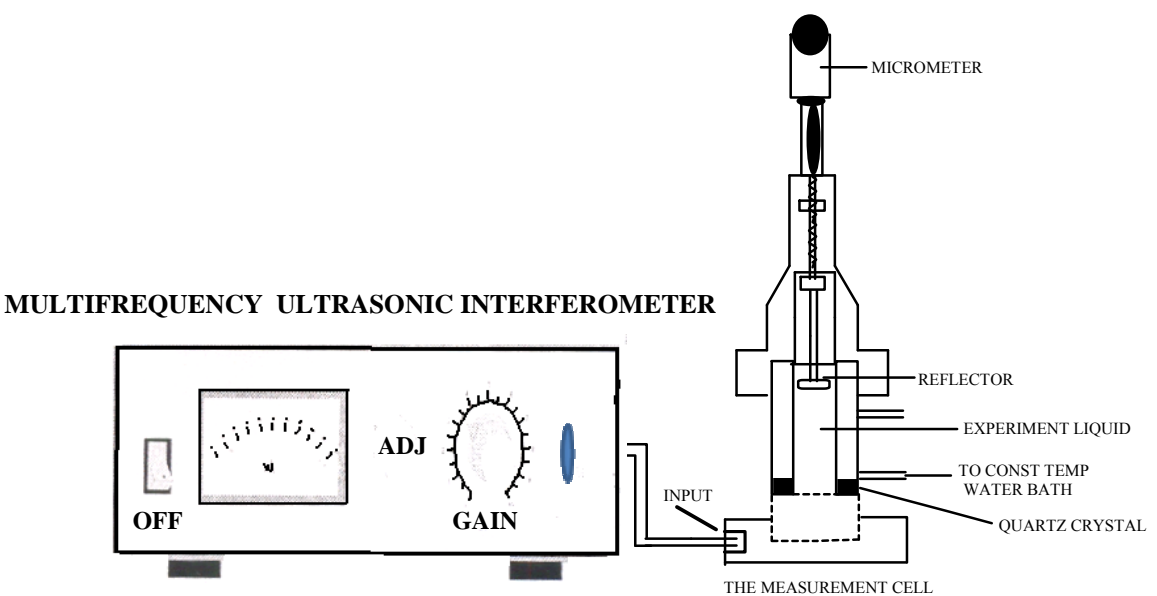

Figure 1. Schematic representation of apparatus used for measuring ultrasonic velocity of liquids

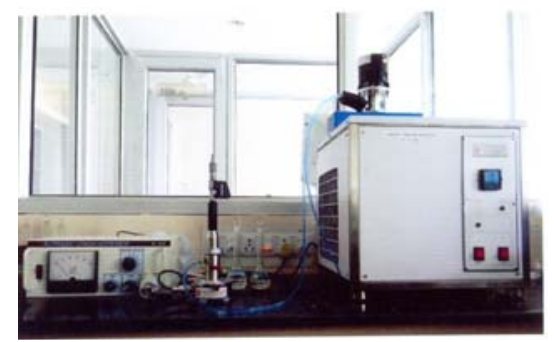

Figure 2. Ultrasonic Interferometer provided by Mittal Enterprises, New Delhi.

If the distance is now increased or decreased and the variation is exactly one half wavelengths or multiple of it, anode current again become maximum. By noting the initial and final position of the micrometer for $\mathrm{n}$ complete movements (maxima-minima-maxima) of the micro-ammeter needle, one can find out the distance $(d)$ moved by the parallel reflector. The wavelength is calculated as,

$$
\lambda=2 d / n
$$

From the knowledge of wavelength ' $\lambda$ ' the velocity ' $v$ ' can obtained by the relation;

$$
u=\lambda x f \mathrm{~ms}^{-1}
$$

\section{Conductivity measurement}

Conductivity measurements are carried out using Conductivity meter. Before and after measurements, the instrument was calibrated with $\mathrm{KCl}$ solution. Each measurement was repeated three times and the average values were calculated.

\section{Theory}

From the observed values the adiabatic compressibility $\left(\beta_{\mathrm{ad}}\right)$, intermolecular free length $\left(L_{\mathrm{f}}\right)$, acoustic impedance $(Z)$, relaxation time $(\tau)$, Rao's constant $\left(R_{\mathrm{M}}\right)$, Wada's constant $(W)$, free volume $\left(V_{\mathrm{f}}\right)$, absorption coefficient $\left(\alpha / f^{2}\right)$, Gibb's free energy $(\Delta G)$, relative association $\left(R_{\mathrm{A}}\right)$ and available volume $\left(V_{\mathrm{a}}\right)$ were calculated. By using ultrasonic velocity data, adiabatic compressibility was calculated by using the equation, 


$$
\beta_{a d}=1 / u^{2} \rho\left(\mathrm{kg}^{-1} \mathrm{~ms}^{-2}\right)
$$

Where, $u=$ velocity $\& \rho=$ density,

Intermolecular free length is determined using the following formula given by Jacobson,

$$
L_{f}=K_{\tau} \beta_{a d}{ }^{1 / 2}(\mathrm{~m})
$$

Acoustic impedance is determined from equation,

$$
Z=u X \rho\left(\mathrm{kg} \mathrm{m}^{-2} \mathrm{~s}^{-1}\right)
$$

The relaxation time $(\tau)$ can be calculated from the relation,

$$
\tau=(4 / 3) \beta \eta(\mathrm{s})
$$

Rao's constant is calculated by using following equation,

$$
R_{M}=\left(M_{e f f} / \rho\right) u^{1 / 2}\left(\mathrm{~m}^{10 / 3} \mathrm{~s}^{-1 / 3} \mathrm{~mol}^{-1}\right)
$$

Wada's constant is calculated by following equation,

$$
W=\left(M_{e f f} / \rho\right) \beta_{a d}^{-1 / 7}\left(\mathrm{~m}^{3} / \operatorname{mole}\left(\mathrm{N} / \mathrm{m}^{2}\right)^{1 / 7}\right)
$$

Free volume is calculated by following equation,

$$
V_{f}=\left(M_{e f f} u / K \eta\right)^{3 / 2}\left(\mathrm{~m}^{3}\right)
$$

Where $M_{\text {eff }}$ is the effective molecular weight, which is expressed as $M_{\text {eff }}=\Sigma M=m_{\mathrm{i}} x_{\mathrm{i}}$ where, $\mathrm{x}$ and $\mathrm{m}$ are the mole fraction and molecular weight of the individual component in the mixture respectively. $\mathrm{K}$ is the temperature independent constant and its value is $4.28 \times 10^{9}$. Absorption coefficient can be calculated using the relation,

$$
\left(\alpha / f^{2}\right)=4 \pi^{2} \tau / 2 u\left(\mathrm{~s}^{2} \mathrm{~m}^{-1}\right)
$$

Gibbs free energy is calculated from acoustic relaxation time $(\tau)$ as follows,

$$
\Delta G=k T \ln (k T \tau / h)\left(\mathrm{Jmol}^{-1}\right)
$$

Relative association is a function of ultrasonic velocity and is calculated by the equation,

$$
R_{A}=\rho / \rho_{o}\left(u_{o} / u\right)^{1 / 3}
$$

The available volume is a direct measure of compactness in the liquid and the strength of attraction between the molecules of a liquid or a liquid mixture. It can be calculated from Schaaf's relation,

$$
V_{a}=V_{m}\left(1-u / u_{x}\right)\left(\mathrm{m}^{3}\right)
$$

\section{Results and Discussion}

The experimentally determined values of density $(\rho)$, viscosity $(\eta)$, ultrasonic velocity $(u)$ and conductivity $(\kappa)$ of two systems at $308.15 \mathrm{~K}$ are represented in Table 1.

The values of adiabatic compressibility $(\beta)$, free length $\left(\mathrm{L}_{\mathrm{f}}\right)$, acoustical impedance $(\mathrm{z})$, relaxation time $(\tau)$ and Rao's constant $\left(\mathrm{R}_{\mathrm{M}}\right)$ of the above two systems are evaluated and are presented Table 2. Table 3 presents Wada's constant $(\mathrm{W})$, free volume $\left(\mathrm{V}_{\mathrm{f}}\right)$, absorption coefficient $\left(\alpha / f^{2}\right)$, Gibb's free energy $(\Delta G)$, relative association $\left(R_{A}\right)$ and available volume $\left(\mathrm{V}_{\mathrm{a}}\right)$. In the present investigation, in all the two liquid systems, viscosity, density, ultrasonic velocity and conductivity increases with increasing molar concentrations of salts. 
Table 1. Experimental parameters $(\rho, \eta$, u and $\kappa)$ for both the systems at $308.15 \mathrm{~K}$

\begin{tabular}{ccccc}
\hline $\begin{array}{c}\text { Concentration } \\
\text { (c) }\end{array}$ & $\rho \times 10^{3} / \mathrm{kgm}^{-3}$ & \multicolumn{1}{c}{$\eta \times 10^{-3} / \mathrm{kgm}^{-1} \mathrm{~s}^{-1}$} & $u \times 10^{3} / \mathrm{ms}^{-1}$ & $\mathrm{k} / \mathrm{mScm}^{-1}$ \\
& \multicolumn{4}{c}{ Aq. NaCl } \\
\hline 0.5 & 0.9971 & 0.7354 & 1.5252 & 9.03 \\
1.0 & 1.0015 & 0.7497 & 1.5312 & 16.42 \\
1.5 & 1.0058 & 0.7636 & 1.5372 & 20.01 \\
2.0 & 1.0101 & 0.7779 & 1.542 & 24.20 \\
2.5 & 1.0139 & 0.7932 & 1.5456 & 29.20 \\
& & Aq. KCl & & \\
0.5 & 1.0010 & 0.7490 & 1.512 & 10.15 \\
1.0 & 1.0042 & 0.7728 & 1.524 & 17.84 \\
1.5 & 1.0077 & 0.7863 & 1.5288 & 21.91 \\
2.0 & 1.0112 & 0.7999 & 1.5324 & 26.30 \\
2.5 & 1.0144 & 0.8132 & 1.536 & 30.61 \\
\hline
\end{tabular}

Table 2. Derived parameters $\left(\beta_{\mathrm{ad}}, L_{\mathrm{f}}, \mathrm{Z}, \tau\right.$ and $\left.\mathrm{R}_{\mathrm{M}}\right)$ for both the systems at $308.15 \mathrm{~K}$

\begin{tabular}{cccccc}
\hline $\begin{array}{c}\text { Concentration } \\
\text { (c) }\end{array}$ & $\begin{array}{c}\beta_{\mathrm{ad}} \times 10^{-10} / \mathrm{N}^{-1} \mathrm{~m}^{2} \\
0.5\end{array}$ & $L_{\mathrm{f}} \times 10^{-11} / \mathrm{m}$ & $\begin{array}{c}Z \times 10^{6} \\
/ \mathrm{kgm}^{-2} \mathrm{~s}^{-1} \\
\mathrm{Aq} . \mathrm{NaCl}\end{array}$ & $\tau \times 10^{-12} / \mathrm{s}$ & $\begin{array}{c}R_{\mathrm{M}} \times 10^{-3} \\
/ \mathrm{m}^{10 / 3} \mathrm{~s}^{-1 / 3} \mathrm{~mol}^{-1}\end{array}$ \\
\hline 1.0 & 4.3113 & 4.3500 & 1.5208 & 0.4227 & 0.2085 \\
1.5 & 4.2588 & 4.3234 & 1.5335 & 0.4257 & 0.2086 \\
2.0 & 4.2075 & 4.2973 & 1.5461 & 0.4284 & 0.2087 \\
2.5 & 4.1636 & 4.2748 & 1.5576 & 0.4318 & 0.2088 \\
& 4.1287 & 4.2569 & 1.5671 & 0.4366 & 0.2089 \\
0.5 & 4.3698 & 4.3794 & 1.5136 & 0.4364 & 0.2072 \\
1.0 & 4.2876 & 4.3380 & 1.5304 & 0.4418 & 0.2078 \\
1.5 & 4.2459 & 4.3169 & 1.5406 & 0.4451 & 0.2081 \\
2.0 & 4.2113 & 4.2992 & 1.5495 & 0.4491 & 0.2084 \\
2.5 & 4.1784 & 4.2824 & 1.5581 & 0.4530 & 0.2087 \\
\hline
\end{tabular}

Table 3. Derived parameters $\left(\mathrm{W}, \mathrm{V}_{\mathrm{f}}, \alpha / \mathrm{f}^{2}, \Delta \mathrm{G}, \mathrm{R}_{\mathrm{A}}, \mathrm{V}_{\mathrm{a}}\right)$ of the two systems at $308.15 \mathrm{~K}$

\begin{tabular}{ccccccc}
\hline $\begin{array}{c}\text { Concentration } \\
(\mathrm{c})\end{array}$ & $\begin{array}{c}W \times 10^{-3} \\
/ \mathrm{m}^{3} / \mathrm{mole}\left(\mathrm{N} / \mathrm{m}^{2}\right)^{1 / 7}\end{array}$ & $\begin{array}{c}V_{\mathrm{f}} \times 10^{-8} \\
/ \mathrm{m}^{3} \mathrm{~mol}^{-1}\end{array}$ & $\begin{array}{c}\alpha / f^{2} \times 10^{-15} \\
/ \mathrm{s}^{2} \mathrm{~m}^{-1} \\
\mathrm{Aq} . \mathrm{NaCl}\end{array}$ & $\begin{array}{c}\Delta G \times 10^{-21} \\
/ \mathrm{Jmol}^{-1}\end{array}$ & $\left(R_{A}\right)$ & $V_{\mathrm{a}} \times 10^{-7} / \mathrm{m}^{3}$ \\
\hline 0.5 & 0.3944 & 2.5894 & 5.4651 & 4.2446 & 0.9976 & 8.4688 \\
1.0 & 0.3947 & 2.5438 & 5.4823 & 4.2747 & 1.0006 & 7.7823 \\
1.5 & 0.3951 & 2.5023 & 5.4955 & 4.3016 & 1.0036 & 7.0980 \\
2.0 & 0.3954 & 2.4579 & 5.5219 & 4.3352 & 1.0069 & 6.5504 \\
2.5 & 0.3958 & 2.4082 & 5.5703 & 4.3822 & 1.0099 & 6.1424 \\
& & & $\mathrm{Aq} . \mathrm{KCl}$ & & & \\
0.5 & 0.3922 & 2.4878 & 5.6914 & 4.3803 & 1.0044 & 9.9278 \\
1.0 & 0.3936 & 2.4159 & 5.7165 & 4.4326 & 1.0049 & 8.5793 \\
1.5 & 0.3942 & 2.3787 & 5.7411 & 4.4642 & 1.0074 & 8.0403 \\
2.0 & 0.3949 & 2.3399 & 5.7791 & 4.5023 & 1.0101 & 7.6366 \\
2.5 & 0.3956 & 2.3041 & 5.8156 & 4.5391 & 1.0125 & 7.2350 \\
\hline
\end{tabular}


The increase of density with increase in concentration of solute suggests a fair strong electrolytic interaction between solute and solvent molecules. The value of adiabatic compressibility $(\beta)$ and intermolecular free length $\left(\mathrm{L}_{\mathrm{f}}\right)$ shows an opposite behaviour as compared to the ultrasonic velocity (u). It is chiefly the compressibility that decreases due to structural changes of molecules in the mixture leading to an increase in ultrasonic velocity. In general $u$ and $L_{f}$ have been reported to vary inversely of each other with the composition of the mixture ${ }^{15-18}$ as in the present system. The free length decrease with increasing solute concentration indicates a significant interaction between solute and solvent molecules. It suggests a structure promoting behaviour on the addition of solute. The conductivity may provide information regarding the nature and strength of forces existing between the ions.

Further, an increase in acoustical impedance $(Z)$ and relaxation time $(\tau)$ with increase in concentration of the salt is noticed in both the systems. The behaviour of acoustic impedance becomes accountable for the transmission of ultrasonic waves. The relaxation time which is in the order of $10^{-12} \mathrm{sec}$ is due to structural relaxation process ${ }^{19}$ and in such a condition it is suggested that the molecules get rearranged due to co-operative process ${ }^{16}$. The increasing trends of Rao's constant or molar sound velocity and Wada's constant or molar compressibility with concentration suggest the availability of more number of components in a given region thus leads to a close packing of the medium and thereby increase the interactions. The values of Wada's constant increase with increasing concentration indicate that there must be tight packing of the medium and hence interaction is increasing. Thus there may be solute-solvent interaction occurring. The molecules of liquid are not closely packed and as such there is always some free space between them. This free space is known as free volume. A decrease in free volume with increase in concentration of the salt is noticed in both the systems which show that solute solvent molecules are coming close to each other and the space between them is decreasing with rise in concentration. This supports to the strong solute -solvent interaction in aqueous solution.

The values of absorption coefficient, Gibb's free energy and relative association listed in the table show increasing trend with concentration whereas the values of available volume decreases with increase in concentration for both the aqueous solutions of sodium chloride and potassium chloride. The increasing value of Gibb's free energy with concentration shows appreciable interaction between solute and solvent molecules. The absorption coefficient trend and available volume trend confirms the earlier conclusions. Relative association evaluate the extent of association of the component in the mixture. The value of relative association increases with increase in concentration signifying strong interionic interaction.

From Figure 3, it is apparent that conductivity increases with increase in concentration for both $\mathrm{NaCl}$ and $\mathrm{KCl}$ solutions. It is found that the $\mathrm{KCl}$ solution shows higher conductivity than $\mathrm{NaCl}$ solution. In the Figures 4 and 5 are presented the values for the adiabatic compressibility and intermolecular free length for aqueous solutions of $\mathrm{NaCl}$ and $\mathrm{KCl}$ versus concentration respectively. The adiabatic compressibility and intermolecular free length values for $\mathrm{NaCl}$ solutions are lesser than that of $\mathrm{KCl}$ solutions. As can be seen from Figure 6 the variation of free volume versus concentration for $\mathrm{NaCl}$ and $\mathrm{KCl}$ solutions. The values of free volume are higher for $\mathrm{NaCl}$ solutions. Figure 7 depicts the variation of Gibb's free energy change versus concentration for both $\mathrm{NaCl}$ and $\mathrm{KCl}$ solutions. 


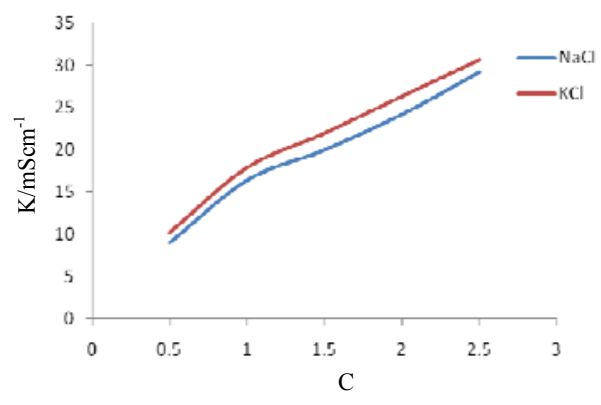

Figure 3. Variation of conductivity $(\kappa)$ versus concentration $(c)$ of aqueous solution of sodium chloride and potassium chloride

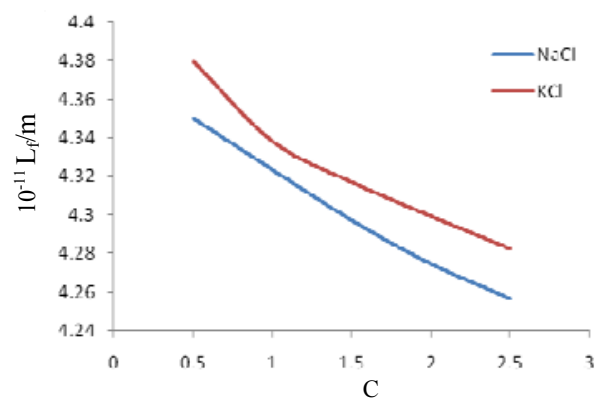

Figure 5. Variation of intermolecular free length $\left(L_{\mathrm{f}}\right)$ versus concentration (c) of aqueous solution of sodium chloride and potassium chloride

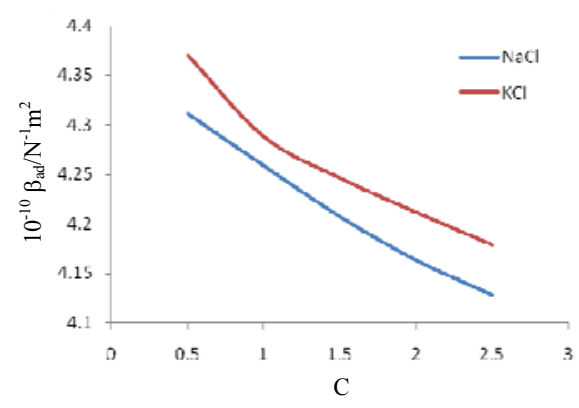

Figure 4. Variation of adiabatic compressibility $\left(\beta_{\text {ad }}\right)$ versus concentration (c) of aqueous solution of sodium chloride and potassium chloride

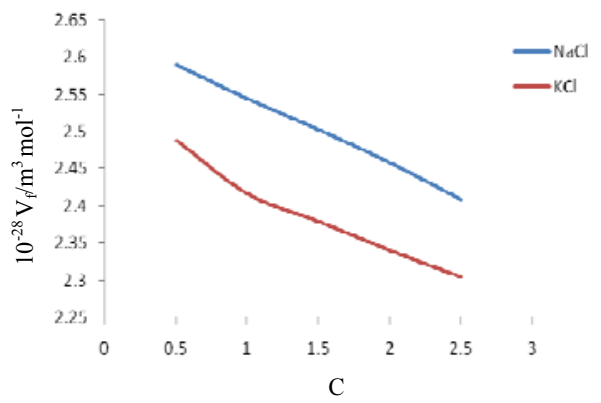

Figure 6. Variation of free volume $\left(V_{\mathrm{f}}\right)$ versus concentration (c) of aqueous solution of sodium chloride and potassium chloride

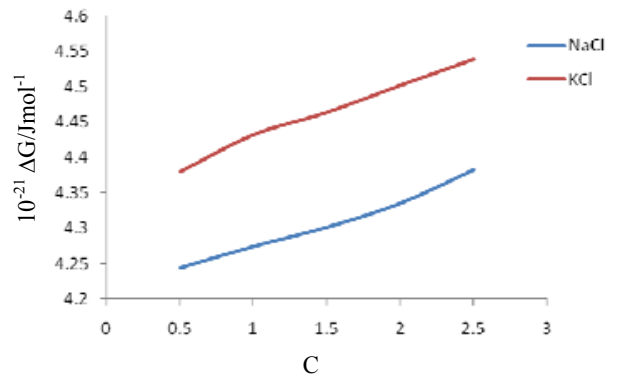

Figure 7. Variation of Gibb's free energy change $(\Delta G)$ versus concentration $(c)$ of aqueous solution of sodium chloride and potassium chloride

The ultrasonic velocity values and other acoustical properties vary with concentration and these variations indicate a greater association of the molecules. The increase in the ultrasonic velocity in any solution usually indicates a greater association of the molecules in them. The greater association is due to ionic hydration of the solute. $\mathrm{NaCl}$ and $\mathrm{KCl}$ are strong electrolytes which dissolve in water to form $\mathrm{Na}^{+}, \mathrm{Cl}^{-}$and $\mathrm{K}^{+}, \mathrm{Cl}^{-}$ions respectively. A greater cohesion in the solution is introduced as water molecules are attached to the ions strongly by electrostatic forces of interaction. 


\section{Comparison of $\mathrm{NaCl}$ and $\mathrm{KCl}$ data}

The ionic radii of sodium, potassium and chlorine are $0.95 \mathrm{~A}^{0}, 1.33 \mathrm{~A}^{0}$ and $1.81 \mathrm{~A}^{0}$. The $\mathrm{Na}^{+}$ ions are more solvated than $\mathrm{K}^{+}$ions because of their size greater than that of $\mathrm{K}^{+}$ions. Due to this, the adiabatic compressibility of $\mathrm{NaCl}$ solution is found to be lesser in comparison with $\mathrm{KCl}$ solution. Also the densities of aqueous solution of $\mathrm{KCl}$ are found to be larger than the densities of aqueous solution of $\mathrm{NaCl}$. It has been found that both $\mathrm{NaCl}$ and $\mathrm{KCl}$ have structure forming tendency in the solvent system. The conductivities of $\mathrm{KCl}$ solution are found to be higher than the conductivities of $\mathrm{NaCl}$ solution. This is because of the fact that smaller ions are largely hydrated than bigger sized ions. So, $\mathrm{Na}^{+}$ions are largely hydrated and hence they are less mobile than $\mathrm{K}^{+}$ions. This leads to higher conductivity values of $\mathrm{KCl}$ solution than $\mathrm{NaCl}$ solution.

\section{Conclusion}

The results of the present study signify that the ultrasonic velocity and other derived acoustic parameters depend on composition of the solution, which is indicative of the presence of molecular interaction. The computed acoustical parameters and their values point to the presence of specific molecular interaction in the mixtures. The systematic study of sodium chloride and potassium chloride in water has been carried out at different concentrations using ultrasonic experiments. The ultrasonic velocity data and other acoustical parameters confer valuable information to comprehend the solute-solvent interactions in the aqueous solutions. Hence it is concluded that the association in these mixtures is the result of electrostatic forces of interaction in binary liquid mixtures.

\section{Conflict of interest}

The authors have no conflict of interest.

\section{Acknowledgement}

The authors are thankful to Department of Chemistry, University of Jammu for financial support.

\section{References}

1. Palaniappan L and Karthikeyan V, Indian J Phys., 2005, 79(2), 155.

2. Nithya R, Mullainathan S, Nithiyanantham S and Rajasekaran R, J Chem., 2009, 6(1), 138-140; DOI:10.1155/2009/589542

3. Nithiyanantham S and Palaniappan L, Acta Ciencia Indica, 2005, 36(4), 533-538.

4. Nithiyanantham S and Palaniappan L Acta Ciencia Indica, 2006, 37(3), 382-392.

5. Nithiyanantham S and Palaniappan L Metals Mater Process, 2008, 20(3), 203.

6. Murty M S, Curr Sci., 1964, 33(12), 364.

7. Soitkar V S and Jajoo S N, Acoust Lett., 1984, 7(12), 1991-1992.

8. Sreekanth K, Sravana K D, Kondaiah M and Krishna Rao D, J Chem Pharm Res., 2011, 3(4), 29-41.

9. Aswale S S, Raghuwanshi P B, Tayde D T and Aswale S R, J Indian Chem Soc., 2007, 84, 159-164.

10. Lagemann L R and Dunbar W S N, J Phys Chem., 1995, 49.

11. Wissler A, J Am Chem Soc., 1949, 71(4), 1272-1274; DOI:10.1021/ja01172a038

12. Bhatti S J, Vivk J S and Sing D P, Acoustica (Germany), 1982, 50, 291.

13. Pandey J D and Shukla A K, J Pure Appl Ultrason., 1982, 15, 37-52.

14. Sharma A K, Sharma M and Lal R, Res J Chem Env., 2010, 14(3), 75. 
15. Ali A, Hyder S and Nain A K, Acoust Lett., 1997, 21, 77.

16. Ali A, Hyder S and Nain A K Indian J Phys., 2000, 74B, 63.

17. Ali A, Hyder S and Kamil M, Thermochem Acta, 1996, 274(25), 209-221; DOI: 10.1016/0040-6031(95)02719-X

18. Eyring H and Kincaid J F, J Chem Phys., 1938, 6, 620-629.

19. Kinsler L E and Rray A R, Fundamentals of Acoustics, Wiley Eastern, New Delhi, 1989. 